University of New Mexico

UNM Digital Repository

Mathematics and Statistics Faculty and Staff

Publications

Academic Department Resources

2019

\title{
A Bipolar Fuzzy Extension of the MULTIMOORA Method
}

Florentin Smarandache

Dragisa Stanujkic

Darjan Karabasevic

Edmundas Kazimieras Zavadskas

Willem Brauer

Follow this and additional works at: https://digitalrepository.unm.edu/math_fsp

Part of the Logic and Foundations Commons, Other Mathematics Commons, and the Set Theory Commons 


\title{
A Bipolar Fuzzy Extension of the MULTIMOORA Method
}

\author{
Dragisa STANUJKIC ${ }^{1 *}$, Darjan KARABASEVIC ${ }^{2}$, \\ Edmundas Kazimieras ZAVADSKAS ${ }^{3}$, Florentin SMARANDACHE ${ }^{4}$, \\ Willem K.M. BRAUERS ${ }^{5}$ \\ ${ }^{1}$ Technical Faculty in Bor, University of Belgrade, Serbia \\ ${ }^{2}$ Faculty of Applied Management, Economics and Finance, \\ University Business Academy in Novi Sad, Belgrade, Serbia \\ ${ }^{3}$ Institute of Sustainable Construction, Labor of Operational Research, \\ Faculty of Civil Engineering, Vilnius Gediminas Technical University, \\ Sauletekio 11, Vilnius, LT-210233, Lithuania \\ ${ }^{4}$ Department of Mathematics, University of New Mexico, \\ 705 Gurley Avenue, Gallup, NM 87301, USA \\ ${ }^{5}$ Faculty of Business and Economics, Department of Economics, \\ University of Antwerp, Antwerp, Belgium \\ e-mail:dstanujkic@tfbor.bg.ac.rs,darjan.karabasevic@mef.edu.rs,edmundas.zavadskas@vgtu.lt, \\ fsmarandache@gmail.com,willem.brauers@uantwerpen.be
}

Received: October 2018; accepted: February 2019

\begin{abstract}
The aim of this paper is to make a proposal for a new extension of the MULTIMOORA method extended to deal with bipolar fuzzy sets. Bipolar fuzzy sets are proposed as an extension of classical fuzzy sets in order to enable solving a particular class of decision-making problems. Unlike other extensions of the fuzzy set of theory, bipolar fuzzy sets introduce a positive membership function, which denotes the satisfaction degree of the element $\mathrm{x}$ to the property corresponding to the bipolar-valued fuzzy set, and the negative membership function, which denotes the degree of the satisfaction of the element $x$ to some implicit counter-property corresponding to the bipolar-valued fuzzy set. By using single-valued bipolar fuzzy numbers, the MULTIMOORA method can be more efficient for solving some specific problems whose solving requires assessment and prediction. The suitability of the proposed approach is presented through an example.
\end{abstract}

Key words: bipolar fuzzy set, single-valued bipolar fuzzy number, MULTIMOORA, MCDM.

\section{Introduction}

The management of very complex systems is the most complex, and therefore the most difficult task of the managers of today's organizations. The effectiveness of the management and managers of an organization depends to a large extent on the quality of the decisions they make on a daily basis.

\footnotetext{
*Corresponding author.
} 
Decision-making and decisions are the core of managerial activities. Bearing in mind the globalization and, therefore, the dynamics of business doing, all of the above-stated have caused business and the decision-making process to become more demanding. Making quality decisions requires an ever more extensive preparation, which also involves the consideration of the different aspects of a decision, for the reason of which the decisionmaking process becomes considerably formalized. Thus, real problems and situations in real life are characterized by a large number of mostly conflicting criteria, whose strict optimization is generally impossible.

When it is necessary to make a decision on choosing one of several potential solutions to a problem, it is desirable to apply one of the models based on multiple-criteria decisionmaking methods (MCDM). This most often involves the process of selecting one of several alternative solutions, for which certain goals are set. When MCDM is concerned, Greco et al. (2010) point out the fact that it is the study of the methods and procedures aimed at making a proposal for solutions in terms of multiple, often conflicting criteria. Hwang and Yoon (1981) states that MCDM is based on the two basic approaches, i.e. on multiple attribute decision-making (MADM), which implies a choice of courses in the presence of multiple, and often conflicting criteria, i.e. a selection of the best alternative from a finite set of possible alternatives. Unlike MADM, in multiple objective decision-making (MODM), the best alternative is that which is formed with multiple goals, based on the continuous variables of the decision with additional constraints.

So, all the problems of today are, in general, multi-criterial, primarily because problems are mainly related to the achievement of the objectives related to a larger number of, usually conflicting, criteria, which is a great approximation to real tasks in decision-making processes (Das et al., 2012; Zavadskas et al., 2014). The increasing application of the MCDM method to solving various problems has caused an exceptional growth of multi-criteria decision-making as an important field of operational research, especially since 1980 (Aouni et al., 2018; Masri, et al., 2018; Wallenius et al., 2008; Dyer et al., 1992).

Within MADM, some of the methods that have been proposed are: Weighted Sum Model (WSM) (Fishburn, 1967); Simple Additive Weighting (SAW) method (MacCrimon, 1968), Elimination Et Choix Traduisant la REalité (ELECTRE) method (Roy, 1968), DEcision-MAking Trial and Evaluation Laboratory (DEMATEL) method (Gabus and Fontela, 1972), Compromise Programming (CP) method (Zeleny, 1973), Simple Multi Attribute Rating Technique (SMART) (Edwards, 1977), Analytic Hierarchy Process (AHP) method (Saaty, 1978), Technique for Order of Preference by Similarity to Ideal Solution (TOPSIS) method (Hwang and Yoon, 1981), Preference Ranking Organization Method for Enrichment Evaluations (PROMETHEE) method (Brans, 1982), Measuring Attractiveness by a Categorical Based Evaluation Technique (MACBETH) (Bana e Costa and Vansnick, 1994), Complex Proportional Assessment of alternatives (COPRAS) method (Zavadskas et al., 1994), Analytic Network Process (ANP) method (Saaty, 1996), Vlse Kriterijumska Optimizacija i kompromisno Resenje (VIKOR) (Opricovic, 1998), Multi-Objective Optimization on basis of Ratio Analysis (MOORA) method (Brauers and Zavadskas, 2006), Additive Ratio ASsessment (ARAS) method (Zavadskas and Turskis, 
2010), Multi-Objective Optimization by Ratio Analysis plus the Full Multiplicative Form (MULTIMOORA) method (Brauers and Zavadskas, 2010a), and so on. While within the MODM methods that have been proposed can be stated: Data envelopment analysis (DEA) method (Charnes et al., 1978), Linear Programming (LP) and Nonlinear Programming (NP) (Luenberger and Ye, 1984), Multi-Objective Programming (MOP) technique (Charnes et al., 1989), Multi-Objective Linear Programming (Ecker and Kouada, 1978), and so on.

The MULTIMOORA method (Brauers and Zavadskas, 2010b) is an important MCDM method that has been applied so far to solve the most diverse problems in the field of economics, management, etc. Basically, the MULTIMOORA method consists of the wellknown MOORA method (Brauers and Zavadskas, 2006) and the method of multi-object optimization (the Full Multiplicative Form of Multiple Objects method). Thus, Brauers and Zavadskas (2010a) proposed the updating of the MOORA method by adding a multiobject optimization method which involves maximizing and minimizing useful multiplicative functions (Lazauskas et al., 2015).

As noted above, the MULTIMOORA method was applied in order to solve a variety of problems, such as: using MULTIMOORA for ranking and selecting the best performance appraisal method (Maghsoodi et al., 2018), project critical path selection (Dorfeshan et al., 2018), the selection of the optimal mining method (Liang et al., 2018), pharmacological therapy selection (Eghbali-Zarch et al., 2018), ICT hardware selection (Adali and Işik, 2017), industrial robot selection (Karande et al., 2016), a CNC machine tool evaluation (Sahu et al., 2016), personnel selection (Karabasevic et al., 2015; Baležentis et al., 2012), the economy (Baležentis and Zeng, 2013; Brauers and Zavadskas, 2011a, 2010b; Brauers and Ginevičius, 2010), and so on.

However, most decisions made in the real world are made in an environment in which goals and constraints cannot be precisely expressed due to their complexity; therefore, a problem cannot be displayed exactly in crisp numbers (Bellman and Zadeh, 1970). For such problems, characterized by uncertainty and indeterminacy, it is more appropriate to use values expressed in intervals instead of concrete (crisp) values. In this case, the existing, ordinary MCDM methods are expanded by using the extensions based on fuzzy sets (Zadeh, 1965), intuitionistic fuzzy sets (Atanassov, 1986), and neutrosophic sets (Smarandache, 1999). Accordingly, in order to allow a much wider use of the MULTIMOORA method, some extensions of the MULTIMOORA method have been proposed, some of which are as follows: Brauers et al. (2011) proposed a fuzzy extension of the MULTIMOORA method; Baležentis and Zeng (2013) proposed an IVFN extension of the MULTIMOORA method; Baležentis et al. (2014) also proposed an IFN extension of the MULTIMOORA method; Stanujkic et al. (2015) proposed an extension of the MULTIMOORA method based on the use of interval-valued triangular fuzzy numbers; Zavadskas et al. (2015) proposed an IVIF-based extension of the MULTIMOORA method; Hafezalkotob et al. (2016) proposed an extension of the MULTIMOORA method based on the use of interval numbers; Stanujkic et al. (2017a) proposed a neutrosophic extension of the MULTIMOORA method, and so on.

In addition to the aforementioned extensions of the fuzzy set theory, Zhang (1994) introduced the concept of bipolar fuzzy sets and proposed the usage of the two membership 
functions that represent membership to a set and membership to a complementary set, thus providing an efficient approach to solving a widely larger number of complex decisionmaking problems.

Despite an advantage that can be achieved by using bipolar fuzzy logic, they are significantly less used for solving MCDM problems compared to other fuzzy logic extensions. The following examples can be mentioned as some of the really rare usages of BFS for solving MCDM problems: Alghamdi et al. (2018) and Akram and Arshad (2018) proposed bipolar fuzzy extensions of TOPSIS and ELECTRE I methods; while Han et al. (2018) provide a comprehensive mathematical approach based on the TOPSIS method for improving the accuracy of bipolar disorder clinical diagnosis.

It is also important to note that these are current researches. In addition, the bipolar logic has been considerably used in the neutrosophic set theory, where Uluçay et al. (2018), Pramanik et al. (018) and Tian et al. (2016) can be cited as some of the current researches.

Therefore, in order to enable a wider use of the MULTIMOORA method for solving even a wider range of problems, a bipolar extension of the MULTIMOORA method is proposed in this paper. Accordingly, the paper is structured as follows: in Section 1, the introductory considerations are presented. In Section 2, some basic definitions regarding bipolar fuzzy sets are given. In Section 3, the ordinary MULTIMOORA method is presented, whereas in Section 4, an extension of the MULTIMOORA method based on single-valued bipolar fuzzy numbers is proposed. In Section 5, a numerical example is demonstrated, and finally, the conclusions are given at the end of the paper.

\section{The Basic Elements of a Bipolar Fuzzy Set}

Definition 1 (Fuzzy set, Zadeh, 1965). Let $X$ be a nonempty set, with a generic element in $X$ denoted by $x$. Then, a fuzzy set $A$ in $X$ is a set of ordered pairs:

$$
A=\left\{\left\langle x, \mu_{A}(x)\right\rangle \mid x \in X\right\}
$$

where the membership function $\mu_{A}(x)$ denotes the degree of the membership of the element $x$ to the set $A$, and $\mu_{A}(x) \in[0,1]$.

Definition 2 (Bipolar fuzzy set, Lee, 2000). Let $X$ be a nonempty set. Then, a bipolar fuzzy set (BFS) is defined as:

$$
A=\left\{\left\langle x, \mu_{A}^{+}(x), v_{A}^{-}(x)\right\rangle \mid x \in X\right\},
$$

where: the positive membership function $\mu_{A}^{+}(x)$ denotes the satisfaction degree of the element $x$ to the property corresponding to the bipolar-valued fuzzy set, and the negative membership function $v_{A}^{-}(x)$ denotes the degree of the satisfaction of the element $x$ to some implicit counter-property corresponding to the bipolar-valued fuzzy set, respectively; $\mu_{A}^{+}(x): X \rightarrow[0,1]$ and $v_{A}^{-}(x): X \rightarrow[-1,0]$. 
Definition 3. A single-valued bipolar fuzzy number (SVBFN) $a=\left\langle a^{+}, a^{-}\right\rangle$is a special bipolar fuzzy set on the real number set $R$, whose positive membership and negative membership function are as follows:

$$
\begin{aligned}
& \mu^{+}(x)= \begin{cases}1 & x=a^{+} \\
0 & \text { otherwise }\end{cases} \\
& v^{-}(x)= \begin{cases}1 & x=a^{-}, \\
0 & \text { otherwise }\end{cases}
\end{aligned}
$$

respectively.

Definition 4. Let $a_{1}=\left\langle a_{1}^{+}, a_{1}^{-}\right\rangle$and $a_{1}=\left\langle a_{2}^{+}, a_{2}^{-}\right\rangle$be two SVBFNs, and $\lambda>0$. Then, the basic operations for these numbers are defined as shown below:

$$
\begin{aligned}
& a_{1}+a_{2}=\left\langle a_{1}^{+}+a_{2}^{+}-a_{1}^{+} a_{2}^{+},-a_{1}^{-} a_{2}^{-}\right\rangle, \\
& a_{1} \cdot a_{2}=\left\langle a_{1}^{+} a_{2}^{+},-\left(-a_{1}^{-}-a_{2}^{-}-a_{1}^{-} a_{2}^{-}\right)\right\rangle, \\
& \lambda a_{1}=\left\langle 1-\left(1-a_{1}^{+}\right)^{\lambda},-\left(-a_{1}^{-}\right)^{\lambda}\right\rangle, \\
& a_{1}^{\lambda}=\left\langle\left(a_{1}^{+}\right)^{\lambda},-\left(1-\left(1-\left(-a_{1}^{-}\right)\right)^{\lambda}\right)\right\rangle .
\end{aligned}
$$

Definition 5. Let $a=\left\langle a^{+}, a^{-}\right\rangle$be an SVBFN. Then, the score function $s_{(a)}$ is as follows:

$$
s_{a}=\left(1+a^{+}+a^{-}\right) / 2
$$

Definition 6. Let $a_{1}$ and $a_{2}$ be two SVBFNs. Then, $a_{1}>a_{2}$ if $s_{a_{1}}>s_{a_{2}}$.

Definition 7. Let $a_{1}=\left\langle a_{1}^{+}, a_{1}^{-}\right\rangle$and $a_{1}=\left\langle a_{2}^{+}, a_{2}^{-}\right\rangle$be two SVBFNs. The Hamming distance between $a_{1}$ and $a_{2}$ is as follows:

$$
d_{H}\left(a_{1}, a_{2}\right)=\frac{1}{2}\left(\left|a_{1}^{+}-a_{2}^{+}\right|+\left|a_{1}^{-}-a_{2}^{-}\right|\right) .
$$

Definition 8. Let $a_{j}=\left\langle a_{j}^{+}, a_{j}^{-}\right\rangle$be a collection of SVBFNs. The bipolar weighted average operator $\left(A_{w}\right)$ of the $n$ dimensions is a mapping as follows:

$$
\begin{aligned}
A_{w}\left(a_{1}, a_{2}, \ldots, a_{n}\right) & =\sum_{j=1}^{n} w_{j} a_{j} \\
& =\left(1-\prod_{j=1}^{n}\left(1-a_{j}^{+}\right)^{w_{j}},-\left(1-\prod_{j=1}^{n}\left(1-\left(-a_{j}^{-}\right)\right)^{w_{j}}\right)\right),
\end{aligned}
$$

where: $w_{j}$ is the element $j$ of the weighting vector, $w_{j} \in[0,1]$ and $\sum_{j=1}^{n} w_{j}=1$. 
Definition 9. Let $a_{j}=\left\langle a_{j}^{+}, a_{j}^{-}\right\rangle$be a collection of SVBFNs. The bipolar weighted geometric operator $\left(G_{w}\right)$ of the $n$ dimensions is a mapping $G_{w}: Q_{n} \rightarrow Q$ as follows:

$$
G_{w}\left(a_{1}, a_{2}, \ldots, a_{n}\right)=\prod_{j=1}^{n} a_{j}^{w_{j}}=\left(\prod_{j=1}^{n}\left(a_{j}^{+}\right)^{w_{j}},-\prod_{j=1}^{n}\left(-a_{j}^{-}\right)^{w_{j}}\right)
$$

\section{The MULTIMOORA Method}

Compared to the other MCDM methods, the MULTIMOORA method is characteristic because it combines three approaches, namely: the Ratio System (RS) Approach, the Reference Point (RP) Approach and the Full Multiplicative Form (FMF) Approach, in order to select the most appropriate alternative.

In addition, this method does not calculate and does not use the overall significance for ranking alternatives and selecting the most appropriate one. Instead of using an overall parameter for ranking alternatives, the final ranking order of the considered alternatives, as well as the selection of the most appropriate alternative, is based on the use of the theory of dominance.

For an MCDM problem that includes the $m$ alternatives that should be evaluated on the basis of the $n$ criteria, the computational procedure of the MULTIMOORA can be expressed as follows:

Step 1. Construct a decision matrix and determine the weights of criteria.

Step 2. Calculate a normalized decision matrix, as follows:

$$
r_{i j}=\frac{x_{i j}}{\sqrt{\sum_{i=1}^{n} x_{i j}^{2}}}
$$

where: $r_{i j}$ denotes the normalized performance of the alternative $i$ with respect to the criterion $j$, and $x_{i j}$ denotes the performance of the alternative $i$ to the criterion $j$.

Step 3. Calculate the overall significance of each alternative, as follows:

$$
y_{i}=\sum_{j \in \Omega_{\max }} w_{j} r_{i j}-\sum_{j \in \Omega_{\min }} w_{j} r_{i j}
$$

where: $y_{i}$ denotes the overall importance of the alternative $i, \Omega_{\max }$ and $\Omega_{\min }$ denote the sets of the benefit cost criteria, respectively.

Step 4. Determine the reference point, as follows:

$$
r^{*}=\left\{r_{1}^{*}, r_{2}^{*}, \ldots, r_{n}^{*}\right\}=\left\{\left(\max _{i} r_{i j} \mid j \in \Omega_{\max }\right),\left(\min _{i} r_{i j} \mid j \in \Omega_{\min }\right)\right\}
$$


Step 5. Determine the maximal distance between each alternative and the reference point, as follows:

$$
d_{i}^{\max }=\max _{j}\left(w_{j}\left|r_{j}^{*}-r_{i j}\right|\right)
$$

where: $d_{i}^{\max }$ denotes the maximal distance of the alternative $i$ to the reference point.

Step 6. Determine the overall utility of each alternative, as follows:

$$
u_{i}=\frac{\prod_{j \in \Omega_{\max }} w_{j} r_{i j}}{\prod_{j \in \Omega_{\min }} w_{j} r_{i j}},
$$

where: $u_{i}$ denotes the overall utility of the alternative $i$.

In particular case, when evaluation is made only on the basis of benefit criteria, Eq. (17) is as follows:

$$
u_{i}=\prod_{j \in \Omega_{\max }} w_{j} r_{i j} .
$$

Step 7. Determine the final ranking order of the considered alternatives and select the most appropriate one. In this step, the considered alternatives are ranked based on their:

- overall significance,

- maximal distance to the reference point, and

- overall utility.

As a result of these rankings, the three different ranking lists are formed, representing the rankings based on the RS approach, the RP approach and the FMF approach of the MULTIMOORA method.

The final ranking of the alternatives is based on the dominance theory, i.e. the alternative with the highest number of appearances in the first positions on all ranking lists is the best-ranked alternative.

\section{An Extension of the MULTIMOORA Method Based on Single-Valued Bipolar Fuzzy Numbers}

For an MCDM problem involving $\mathrm{m}$ alternatives and $\mathrm{n}$ criteria and $\mathrm{K}$ decision-makers, whereby the performances of the alternatives are expressed by using SVBFNs, the calculation procedure of the extended MULTIMOORA method can be expressed as follows:

Step 1. Evaluate the alternatives in relation to the evaluation criteria, and do that for each DM. In this step, each DM evaluates the alternatives and forms an evaluation matrix.

In order to provide an easier evaluation, the following Likert scale, shown in Table 1, is proposed for evaluating alternatives in relation to the evaluation criteria. 
Table 1

Nine-point Likert scale for expressing degree of satisfaction.

\begin{tabular}{ll}
\hline Satisfaction level & Numerical value \\
\hline Neutral/without attitude & 0 \\
Extremely low & 1 \\
Very low & 2 \\
Low & 3 \\
Medium low & 4 \\
Medium & 5 \\
Medium high & 6 \\
High & 7 \\
Very high & 8 \\
Extremely high & 9 \\
Absolute & 10 \\
\hline
\end{tabular}

However, the respondents should be introduced that the values listed in Table 1 are only approximative and that they can use any value from the interval $[0,10]$ and $[-10,0]$.

After forming initial decision-making matrix, obtained responses should be divided by 10 in order to transform it into the allowed interval $[-1,1]$. This approach for evaluating alternatives is proposed to avoid the use of vector normalization procedure, used in the ordinary MULTIMOORA method.

Step 2. Determine the importance of the evaluation criteria, and do that for each DM. In this step, each DM determines the weights of the criteria by using one of several existing methods for determining the weights of criteria.

Step 3. Determine the group decision matrix. In order to transform individual into group preferences, individual evaluation matrices are transformed into group one by applying Eq. (11).

Step 4. Determine the group weights of the criteria. In order to transform individual into group preferences with respect to the weights of criteria, the group weights of criteria can be determined as follows:

$$
w_{j}=\sum_{k=1}^{K} w_{j}^{k}
$$

where: $w_{j}$ denotes the weight of the criterion $j$, and $w_{j}^{k}$ denotes the weight of the criterion $j$ obtained from the DM $k$.

After calculating the group evaluation matrix and the group weights of the criteria, all the necessary prerequisites for applying all the three approaches integrated in the MULTIMOORA method are obtained. Based on the approach proposed by Stanujkic et al. (2017b), the remainder steps of the proposed approach are as follows:

Step 5. Determine the significance of the evaluated alternatives based on the RS approach. This step can be explained through the following sub-steps: 
Step 5.1. Determine the impact of the benefit and cost criteria to the importance of each alternative, as follows:

$$
\begin{aligned}
& Y_{i}^{+}=\left(1-\prod_{j \in \Omega_{\max }}^{n}\left(1-r_{i j}\right)^{w_{j}},-\left(1-\prod_{j \in \Omega_{\max }}^{n}\left(1-\left(-r_{i j}\right)\right)^{w_{j}}\right),\right. \\
& Y_{i}^{-}=\left(1-\prod_{j \in \Omega_{\min }}^{n}\left(1-r_{i j}\right)^{w_{j}},-\left(1-\prod_{j \in \Omega_{\min }}^{n}\left(1-\left(-r_{i j}\right)\right)^{w_{j}}\right),\right.
\end{aligned}
$$

where: $Y_{i}^{+}$and $Y_{i}^{-}$denote the importance of the alternative $i$ obtained on the basis of the benefit and cost criteria, respectively; $Y_{i}^{+}$and $Y_{i}^{-}$are SVBFNs.

It is evident that $A_{w}$ operator is used to calculate the impact of the benefit and cost criteria.

Step. 5.2. Transform $Y_{i}^{+}$and $Y_{i}^{-}$into crisp values by using the Score Function, as follows:

$$
\begin{aligned}
& y_{i}^{+}=s\left(Y_{i}^{+}\right), \\
& y_{i}^{-}=s\left(Y_{i}^{-}\right) .
\end{aligned}
$$

Step 5.3. Calculate the overall importance for each alternative, as follows:

$$
y_{i}=y_{i}^{+}-y_{i}^{-}
$$

Step 6. Determine the significance of the evaluated alternatives based on the RP approach. This step can be explained through the following sub-steps:

Step 6.1. Determine the reference point. The coordinates on the bipolar fuzzy reference point $r^{*}=\left\{r_{1}^{*}, r_{2}^{*}, \ldots, r_{n}^{*}\right\}$ can be determined as follows:

$$
r^{*}=\left\{\left(\left\langle\max _{i} r_{i j}, \min _{i} r_{i j}\right\rangle \mid j \in \Omega_{\max }\right),\left(\left\langle\min _{i} r_{i j}, \max _{i} r_{i j}\right\rangle \mid j \in \Omega_{\min }\right)\right\}
$$

where: $r_{j}^{*}$ denotes the coordinate $j$ of the reference point.

Step 6.2. Determine the maximum distance from each alternative to all the coordinates of the reference point. The maximum distance of each alternative to the reference point can be determined as follows:

$$
d_{i j}^{\max }=d_{\max }\left(r_{i j}, r_{j}^{*}\right) w_{j},
$$

where $d_{i j}^{\max }$ denotes the maximum distance of the alternative $i$ to the criterion $j$ determined by Eq. (10).

Step 6.3. Determine the maximum distance of each alternative, as follows:

$$
d_{i}^{\max }=\max _{j} d_{i j}^{\max }
$$

where $d_{i}^{\max }$ denotes the maximum distance of the alternative $i$. 
Step 7. Determine the significance of the evaluated alternatives based on the FMF.

This step can be explained through the following sub-steps:

Step 7.1. Calculate the utility obtained based on the benefit $U_{i}^{+}$and cost $U_{i}^{-}$criteria, for each alternative, as follows:

$$
\begin{aligned}
& U_{i}^{+}=\left(\prod_{j \in \Omega_{\max }}^{n}\left(r_{i j}\right)^{w_{j}},-\prod_{j \in \Omega_{\max }}^{n}\left(-r_{i j}\right)^{w_{j}}\right), \\
& U_{i}^{-}=\left(\prod_{j \in \Omega_{\text {min }}}^{n}\left(r_{i j}\right)^{w_{j}},-\prod_{j \in \Omega_{\min }}^{n}\left(-r_{i j}\right)^{w_{j}}\right),
\end{aligned}
$$

where $U_{i}^{+}$and $U_{i}^{-}$are SVBFNs.

Step 7.2. Transform $U_{i}^{+}$and $U_{i}^{-}$into crisp values by using the Score Function, as follows:

$$
\begin{aligned}
& u_{i}^{+}=s\left(U_{i}^{+}\right), \\
& u_{i}^{-}=s\left(U_{i}^{-}\right) .
\end{aligned}
$$

Step 7.3. Determine the overall utility for each alternative, as follows:

$$
u_{i}=\frac{u_{i}^{+}}{u_{i}^{-}} .
$$

In the case when evaluation is made only on the basis of benefit criteria, Eq. (32) is as follows:

$$
u_{i}=u_{i}^{+}
$$

Step 8. Determine the final ranking order of the alternatives. The final ranking order of the alternatives can be determined as in the case of the ordinary MULTIMOORA method, i.e. based on the dominance theory (Brauers and Zavadskas, 2011b).

In this stage, the alternatives are ranked based on their overall importance, maximum distance to the reference point and overall utility. As a result of that, three ranking lists are formed.

Based on these ranking lists, the final ranking list of the alternatives is formed on the basis of the theory of dominance, i.e. the alternative with the largest number of appearances on the first position in the three ranking lists is the most acceptable.

\section{A Numerical Example}

In this section, a numerical example of purchasing rental space is considered in order to explain the proposed approach in detail. 
Table 2

The ratings obtained from the first of the three DMs.

\begin{tabular}{|c|c|c|c|c|c|c|c|c|c|c|}
\hline & \multicolumn{2}{|c|}{$C_{1}$} & \multicolumn{2}{|c|}{$C_{2}$} & \multicolumn{2}{|c|}{$C_{3}$} & \multicolumn{2}{|c|}{$C_{4}$} & \multicolumn{2}{|c|}{$C_{5}$} \\
\hline & $a^{+}$ & $a^{-}$ & $a^{+}$ & $a^{-}$ & $a^{+}$ & $a^{-}$ & $a^{+}$ & $a^{-}$ & $a^{+}$ & $a^{-}$ \\
\hline$A_{1}$ & 7 & -2 & 7 & -3 & 5 & -1 & 7 & -5 & 8 & -1 \\
\hline$A_{2}$ & 4 & -1 & 5 & -2 & 4 & -2 & 4 & -6 & 7 & -1 \\
\hline$A_{3}$ & 7 & -1 & 3 & -1 & 2 & 0 & 2 & -1 & 7 & -2 \\
\hline$A_{4}$ & 9 & -1 & 4 & -1 & 3 & 0 & 3 & -1 & 6 & -1 \\
\hline
\end{tabular}

Table 3

The ratings obtained from the first of the three DMs, in the form of SVBFNs.

\begin{tabular}{llllll}
\hline & $C_{1}$ & $C_{2}$ & $C_{3}$ & $C_{4}$ & $C_{5}$ \\
\hline$A_{1}$ & $\langle 0.70,-0.20\rangle$ & $\langle 0.70,-0.30\rangle$ & $\langle 0.50,-0.10\rangle$ & $\langle 0.70,-0.50\rangle$ & $\langle 0.80,-0.10\rangle$ \\
$A_{2}$ & $\langle 0.40,-0.10\rangle$ & $\langle 0.50,-0.20\rangle$ & $\langle 0.40,-0.20\rangle$ & $\langle 0.40,-0.60\rangle$ & $\langle 0.70,-0.10\rangle$ \\
$A_{3}$ & $\langle 0.70,-0.10\rangle$ & $\langle 0.30,-0.10\rangle$ & $\langle 0.20,0.00\rangle$ & $\langle 0.20,-0.10\rangle$ & $\langle 0.70,-0.20\rangle$ \\
$A_{4}$ & $\langle 0.90,-0.10\rangle$ & $\langle 0.40,-0.10\rangle$ & $\langle 0.30,0.00\rangle$ & $\langle 0.30,-0.10\rangle$ & $\langle 0.60,-0.10\rangle$ \\
\hline
\end{tabular}

Table 4

The ratings obtained from the second of the three DMs, in the form of SVBFNs.

\begin{tabular}{llllll}
\hline & $C_{1}$ & $C_{2}$ & $C_{3}$ & $C_{4}$ & $C_{5}$ \\
\hline$A_{1}$ & $\langle 0.70,-0.20\rangle$ & $\langle 0.70,-0.50\rangle$ & $\langle 0.40,-0.20\rangle$ & $\langle 0.70,-0.50\rangle$ & $\langle 0.80,-0.10\rangle$ \\
$A_{2}$ & $\langle 0.60,-0.10\rangle$ & $\langle 0.40,-0.60\rangle$ & $\langle 0.40,-0.20\rangle$ & $\langle 0.40,-0.60\rangle$ & $\langle 0.80,-0.10\rangle$ \\
$A_{3}$ & $\langle 0.80,-0.10\rangle$ & $\langle 0.20,-0.10\rangle$ & $\langle 0.20,-0.10\rangle$ & $\langle 0.20,-0.10\rangle$ & $\langle 0.70,-0.10\rangle$ \\
$A_{4}$ & $\langle 0.90,-0.10\rangle$ & $\langle 0.30,-0.10\rangle$ & $\langle 0.30,-0.10\rangle$ & $\langle 0.30,-0.10\rangle$ & $\langle 0.60,-0.10\rangle$ \\
\hline
\end{tabular}

Suppose that a company is planning to start its sales business in a new location, and therefore is looking for a new sales building. After the initial consideration of the available alternatives, four alternatives have been identified as suitable. For this reason, a team of three decision-makers (DMs) was formed with the aim of evaluating suitable alternatives based on the following criteria:

$-C_{1}-$ Rental space quality;

- $C_{2}-$ Rental space adequacy;

- $C_{3}$ - Location quality;

- $C_{4}$ - Location distance from the city centre, and

$-C_{5}-$ Rental price.

As previously reasoned, in this evaluation the ratings of the alternatives in relation to the criteria are expressed by using SVBFNs.

The ratings obtained from the first of the three DMs are shown in Table 2, as the points of the Likert scale, whereas in Table 3, they are shown in the form of SVBFNs.

The ratings obtained from the second and the third of the three DMs are accounted for in Table 4 and Table 5.

The group decision matrix, calculated by applying Eq. (11), is presented in Table 6 . 
Table 5

The ratings obtained from the third of the three DMs, in the form of SVBFNs.

\begin{tabular}{llllll}
\hline & $C_{1}$ & $C_{2}$ & $C_{3}$ & $C_{4}$ & $C_{5}$ \\
\hline$A_{1}$ & $\langle 0.60,-0.10\rangle$ & $\langle 0.90,-0.20\rangle$ & $\langle 1.00,0.00\rangle$ & $\langle 1.00,0.00\rangle$ & $\langle 0.80,-0.10\rangle$ \\
$A_{2}$ & $\langle 0.40,-0.60\rangle$ & $\langle 0.40,-0.60\rangle$ & $\langle 1.00,-0.40\rangle$ & $\langle 1.00,0.00\rangle$ & $\langle 0.80,-0.10\rangle$ \\
$A_{3}$ & $\langle 0.20,-0.10\rangle$ & $\langle 0.90,-0.40\rangle$ & $\langle 0.80,-0.30\rangle$ & $\langle 0.70,-0.10\rangle$ & $\langle 0.70,-0.10\rangle$ \\
$A_{4}$ & $\langle 0.30,-0.10\rangle$ & $\langle 1.00,-0.30\rangle$ & $\langle 0.80,-0.20\rangle$ & $\langle 0.80,-0.10\rangle$ & $\langle 0.60,-0.10\rangle$ \\
\hline
\end{tabular}

Table 6

The group decision-making matrix.

\begin{tabular}{llllll}
\hline & $C_{1}$ & $C_{2}$ & $C_{3}$ & $C_{4}$ & $C_{5}$ \\
\hline$A_{1}$ & $\langle 0.67,-0.16\rangle$ & $\langle 0.79,-0.32\rangle$ & $\langle 1.00,0.00\rangle$ & $\langle 1.00,0.00\rangle$ & $\langle 0.80,-0.10\rangle$ \\
$A_{2}$ & $\langle 0.47,-0.18\rangle$ & $\langle 0.43,-0.42\rangle$ & $\langle 1.00,-0.26\rangle$ & $\langle 1.00,0.00\rangle$ & $\langle 0.77,-0.10\rangle$ \\
$A_{3}$ & $\langle 0.64,-0.10\rangle$ & $\langle 0.61,-0.16\rangle$ & $\langle 0.49,0.00\rangle$ & $\langle 0.41,-0.10\rangle$ & $\langle 0.70,-0.13\rangle$ \\
$A_{4}$ & $\langle 0.81,-0.10\rangle$ & $\langle 1.00,-0.15\rangle$ & $\langle 0.53,0.00\rangle$ & $\langle 0.53,-0.10\rangle$ & $\langle 0.60,-0.10\rangle$ \\
\hline
\end{tabular}

Table 7

The weights of the criteria obtained from the first of the three DMs.

\begin{tabular}{lllll}
\hline & $s_{j}$ & $k_{j}$ & $q_{j}$ & $w_{j}$ \\
\hline$C_{1}$ & & 1 & 1 & 0.19 \\
$C_{2}$ & 1.2 & 0.80 & 1.25 & 0.23 \\
$C_{3}$ & 0.9 & 1.10 & 1.14 & 0.21 \\
$C_{4}$ & 0.7 & 1.30 & 0.87 & 0.16 \\
$C_{5}$ & 1.2 & 0.80 & 1.09 & 0.20 \\
& & 5.00 & 5.35 & 1.00 \\
\hline
\end{tabular}

Table 8

The group criteria weights.

\begin{tabular}{lllll}
\hline & $w_{j}^{1}$ & $w_{j}^{2}$ & $w_{j}^{3}$ & $w_{j}$ \\
\hline$C_{1}$ & 0.19 & 0.17 & 0.19 & 0.18 \\
$C_{2}$ & 0.23 & 0.24 & 0.23 & 0.24 \\
$C_{3}$ & 0.21 & 0.22 & 0.21 & 0.21 \\
$C_{4}$ & 0.16 & 0.17 & 0.16 & 0.16 \\
$C_{5}$ & 0.20 & 0.21 & 0.20 & 0.21 \\
& & & & 1.00 \\
\hline
\end{tabular}

The weights obtained from the first of the three DMs by applying the PIPRECIA method (Stanujkic et al., 2017b) are accounted for in Table 7, while the group weights of the criteria, calculated by applying Eq. (19), are shown in Table 8 .

On the basis of the ratings from Table 6 and the weights from Table 8 , the overall significance, the maximum distance to the reference point and the overall utility are calculated for each alternative in the next step.

The overall significances, accounted for in Table 9, are calculated by applying Eqs. (20)-(24). 
Table 9

The overall significances of the considered alternatives.

\begin{tabular}{lllllll}
\hline & $Y_{i}^{+}$ & $Y_{i}^{-}$ & $y_{i}^{+}$ & $y_{i}^{-}$ & $y_{i}$ & Rank \\
\hline$A_{1}$ & $\langle 1.00,-0.11\rangle$ & $\langle 1.00,-0.02\rangle$ & 0.94 & 0.99 & -0.05 & 3 \\
$A_{2}$ & $\langle 1.00,-0.20\rangle$ & $\langle 1.00,-0.02\rangle$ & 0.90 & 0.99 & -0.09 & 4 \\
$A_{3}$ & $\langle 0.42,-0.06\rangle$ & $\langle 0.30,-0.05\rangle$ & 0.68 & 0.63 & 0.05 & 2 \\
$A_{4}$ & $\langle 1.00,-0.06\rangle$ & $\langle 0.29,-0.04\rangle$ & 0.97 & 0.62 & 0.35 & 1 \\
\hline
\end{tabular}

Table 10

The reference points.

\begin{tabular}{lllll}
\hline & \multicolumn{2}{c}{$\Omega_{\max }$} & \multicolumn{2}{c}{$\Omega_{\min }$} \\
\hline & $r^{+}$ & $r^{-}$ & $r^{+}$ & $r^{-}$ \\
\hline$r^{*}$ & 1.00 & -0.20 & 0.29 & -0.02 \\
\hline
\end{tabular}

Table 11

The ratings of the alternatives obtained based on the reference point approach.

\begin{tabular}{llllllll}
\hline & $C_{1}$ & $C_{2}$ & $C_{3}$ & $C_{4}$ & $C_{5}$ & $d_{i}^{\max }$ & Rank \\
\hline$A_{1}$ & 0.08 & 0.16 & 0.13 & 0.29 & 0.10 & 0.08 & 4 \\
$A_{2}$ & 0.17 & 0.28 & 0.00 & 0.29 & 0.09 & 0.00 & 1 \\
$A_{3}$ & 0.13 & 0.33 & 0.38 & 0.05 & 0.06 & 0.05 & 3 \\
$A_{4}$ & 0.04 & 0.14 & 0.36 & 0.11 & 0.00 & 0.00 & 1 \\
\hline
\end{tabular}

Table 12

The overall utility of the considered alternatives.

\begin{tabular}{cccccccc}
\hline & $U_{i}^{+}$ & $U_{i}^{-}$ & $u_{i}^{+}$ & $u_{i}^{-}$ & $u_{i}$ & Rank & \\
\hline$A_{1}$ & $\langle 1.00,-0.11\rangle$ & $\langle 1.00,-0.02\rangle$ & 0.94 & 0.99 & -0.05 & 3 \\
$A_{2}$ & $\langle 1.00,-0.20\rangle$ & $\langle 1.00,-0.02\rangle$ & 0.90 & 0.99 & -0.09 & 4 \\
$A_{3}$ & $\langle 0.42,-0.06\rangle$ & $\langle 0.30,-0.05\rangle$ & 0.68 & 0.63 & 0.05 & 2 \\
$A_{4}$ & $\langle 1.00,-0.06\rangle$ & $\langle 0.29,-0.04\rangle$ & 0.97 & 0.62 & 0.35 & 1 \\
\hline
\end{tabular}

After that, the reference point shown in Table 10 is determined by applying Eq. (25).

The maximum distances to the reference point accounted for in Table 11 are determined by applying Eq. (26) and Eq. (27).

The overall utility shown in Table 12 is calculated by applying Eqs. (28)-(32).

Finally, on the basis of the ranking orders shown in Tables 9, 11 and 12, the most appropriate alternative is determined by means of the theory of dominance, as is shown in Table 13.

As can be seen from Table 12, the most appropriate alternative is the alternative denoted as $A_{4}$. 
Table 13

The final ranking order of the considered alternatives.

\begin{tabular}{lllll}
\hline & $R S$ & $R P$ & $F M P$ & Final rank \\
\hline$A_{1}$ & 3 & 4 & 3 & 3 \\
$A_{2}$ & 4 & 1 & 4 & 4 \\
$A_{3}$ & 2 & 3 & 2 & 2 \\
$A_{4}$ & 1 & 1 & 1 & 1 \\
\hline
\end{tabular}

\section{Conclusions}

The bipolar fuzzy sets introduced two membership functions, namely the membership function to a set and the membership function to a complementary set.

On the other hand, the MULTIMOORA method is an efficient and already proven multiple-criteria decision-making method, which has been used for solving a number of different decision-making problems so far.

Therefore, an extension of the MULTIMOORA method enabling the use of singlevalued bipolar fuzzy numbers is proposed in this article. The usability and efficiency of the proposed extension is successfully demonstrated on the example of the problem of the best location selection.

In the literature, numerous extensions of the MULTIMOORA methods have been proposed with the aim to adapt it for the use of grey system theory, fuzzy set theory, as well as various extensions of fuzzy set theory. Some extensions that enable the use of neutrosophic sets are also proposed. The mentioned extensions aim to exploit the specificities of particular sets for solving certain types of decision-making problems, and thus enable more efficient decision making.

Because of the specificity that bipolar fuzzy sets provide, the proposed expanded MULTIMOORA method can be expected to be acceptable for solving a particular class of complex decision-making problems.

\section{References}

Adali, E.A., Işik, A.T. (2017). The multi-objective decision making methods based on MULTIMOORA and MOOSRA for the laptop selection problem. Journal of Industrial Engineering International, 13(2), 229237.

Akram, M., Arshad, M. (2018). A novel trapezoidal bipolar fuzzy TOPSIS method for group decision-making. Group Decision and Negotiation, 1-20.

Alghamdi, M.A., Alshehri, N.O., Akram, M. (2018). Multi-criteria decision-making methods in bipolar fuzzy environment. International Journal of Fuzzy Systems, 20(6), 2057-2064.

Aouni, B., Doumpos, M., Pérez-Gladish, B., Steuer, R.E. (2018). On the increasing importance of multiple criteria decision aid methods for portfolio selection. Journal of the Operational Research Society, 69(10), 1525-1542.

Atanassov, K.T. (1986). Intuitionistic fuzzy sets. Fuzzy Sets and Systems, 20(1), 87-96.

Baležentis, T., Zeng, S. (2013). Group multi-criteria decision making based upon interval-valued fuzzy numbers: an extension of the MULTIMOORA method. Expert Systems with Applications, 40(2), 543-550.

Baležentis, A., Baležentis, T., Brauers, W.K. (2012). MULTIMOORA-FG: a multi-objective decision making method for linguistic reasoning with an application to personnel selection. Informatica, 23(2), 173-190. 
Baležentis, T., Zeng, S., Balezentis, A. (2014), MULTIMOORA-IFN: a MCDM method based on intuitionistic fuzzy number for performance management, Economic Computation and Economic Cybernetics Studies and Research, 48(4), 85-102.

Bana e Costa, C.A., Vansnick, J.C. (1994). MACBETH - an interactive path towards the construction of cardinal value functions. International Transactions in Operational Research, 1(4), 489-500.

Bellman, R.E., Zadeh, L.A. (1970). Decision-making in a fuzzy environment. Management Science, 17(4), 141164.

Brans, J.P., (1982). Língénierie de la décision. Elaboration dínstruments dáide à la décision. Méthode PROMETHEE. In: Nadeau, R., Landry, M. (Eds.), L'aide a la Décision: Nature, Instruments et Perspectives d'avenir. Presses de 1’Université Laval, Québec, Canada, pp. 183-214.

Brauers, W.K.M., Ginevičius, R. (2010). The economy of the Belgian regions tested with MULTIMOORA. Journal of Business Economics and Management, 11(2), 173-209.

Brauers, W.K., Zavadskas, E.K. (2006). The MOORA method and its application to privatization in a transition economy. Control and Cybernetics, 35(2), 445-469.

Brauers, W.K.M., Zavadskas, E.K. (2010a). Project management by MULTIMOORA as an instrument for transition economies. Technological and Economic Development of Economy, 16(1), 5-24.

Brauers, W.K.M., Zavadskas, E.K. (2010b). Robustness in the MULTIMOORA model: the example of Tanzania. Transformations in Business and Economics, 9(3), 67-83.

Brauers, W.K.M., Zavadskas, E.K. (2011a). From a centrally planned economy to multiobjective optimization in an enlarged project management: the case of China. Economic Computation and Economic Cybernetics Studies and Research, 45(1), 167-188.

Brauers, W.K.M., Zavadskas, E.K. (2011b). Multimoora optimization used to decide on a bank loan to buy property. Technological and Economic Development of Economy, 17(1), 174-188.

Brauers, W.K., Balezentis, A., Balezentis, T. (2011). MULTIMOORA for the EU Member States updated with fuzzy number theory. Technological and Economic Development of Economy, 17(2), 259-290.

Charnes, A., Cooper, W.W., Rhodes, E. (1978). Measuring the efficiency of decision making units. European journal of operational research, 2(6), 429-444.

Charnes, A., Cooper, W.W., Wei, Q.L., Huang, Z.M. (1989). Cone ratio data envelopment analysis and multiobjective programming. International Journal of Systems Science, 20(7), 1099-1118.

Das, M.C., Sarkar, B., Ray, S. (2012). Decision making under conflicting environment: a new MCDM method. International Journal of Applied Decision Sciences, 5(2), 142-162.

Dorfeshan, Y., Mousavi, S.M., Mohagheghi, V., Vahdani, B. (2018). Selecting project-critical path by a new interval type-2 fuzzy decision methodology based on MULTIMOORA, MOOSRA and TPOP methods. Computers and Industrial Engineering, 120, 160-178.

Dyer, J.S., Fishburn, P.C., Steuer, R.E., Wallenius, J., Zionts, S. (1992). Multiple criteria decision making, multiattribute utility theory: the next ten years. Management Science, 38(5), 645-654.

Ecker, J.G., Kouada, I.A. (1978). Finding all efficient extreme points for multiple objective linear programs. Mathematical Programming, 14(1), 249-261.

Edwards, W. (1977). 12 use of multiattribute utility measurement for social decision making. Conflicting, 247.

Eghbali-Zarch, M., Tavakkoli-Moghaddam, R., Esfahanian, F., Sepehri, M.M., Azaron, A. (2018). Pharmacological therapy selection of type 2 diabetes based on the SWARA and modified MULTIMOORA methods under a fuzzy environment. Artificial Intelligence in Medicine, 87, 20-33.

Fishburn, P.C. (1967). Letter to the editor - additive utilities with incomplete product sets: application to priorities and assignments. Operations Research, 15(3), 537-542.

Gabus, A., Fontela, E. (1972). World Problems, an Invitation to Further Thought within the Framework of DEMATEL. Battelle Geneva Research Center, Geneva, Switzerland, 1-8.

Greco, S., Slowiński, R., Figueira, J.R., Mousseau, V. (2010). Robust ordinal regression. In: Trends in Multiple Criteria Decision Analysis. Springer, Boston, MA, pp. 241-283.

Hafezalkotob, A., Hafezalkotob, A., Sayadi, M.K. (2016). Extension of MULTIMOORA method with interval numbers: an application in materials selection. Applied Mathematical Modelling, 40(2), 1372-1386.

Han, Y., Lu, Z., Du, Z., Luo, Q., Chen, S. (2018). A YinYang bipolar fuzzy cognitive TOPSIS method to bipolar disorder diagnosis. Computer Methods and Programs in Biomedicine, 158, 1-10.

Hwang, C.L., Yoon, K. (1981). Methods for multiple attribute decision making. In Multiple Attribute Decision Making. Springer, Berlin, Heidelberg, 58-191.

Karabasevic, D., Stanujkic, D., Urosevic, S., Maksimovic, M. (2015). Selection of candidates in the mining industry based on the application of the SWARA and the MULTIMOORA methods. Acta Montanistica Slovaca, 20(2), 116-124. 
Karande, P., Zavadskas, E., Chakraborty, S. (2016). A study on the ranking performance of some MCDM methods for industrial robot selection problems. International Journal of Industrial Engineering Computations, 7(3), 399-422.

Lazauskas, M., Kutut, V., Zavadskas, E.K. (2015). Multicriteria assessment of unfinished construction projects. Gradevinar, 67(04.), 319-328.

Lee, K.M. (2000). Bipolar-valued fuzzy sets and their basic operations. In: Proceeding International Conference, Bangkok, Thailand, pp. 307-317.

Liang, W., Zhao, G., Hong, C. (2018). Selecting the optimal mining method with extended multi-objective optimization by ratio analysis plus the full multiplicative form (MULTIMOORA) approach. Neural Computing and Applications, 1-16.

Luenberger, D.G., Ye, Y. (1984). Linear and Nonlinear Programming, Vol. 2. Addison-Wesley, Reading, MA.

MacCrimon, K.R. (1968). Decision Marking Among Multiple-Attribute Alternatives: a Survey and Consolidated Approach. RAND Memorandum, RM-4823-ARPA. The Rand Corporation, Santa Monica, CA.

Maghsoodi, A.I., Abouhamzeh, G., Khalilzadeh, M., Zavadskas, E.K. (2018). Ranking and selecting the best performance appraisal method using the MULTIMOORA approach integrated Shannon's entropy. Frontiers of Business Research in China, 12(1), 2.

Masri, H., Pérez-Gladish, B., Zopounidis, C. (2018). Financial Decision Aid Using Multiple Criteria: Recent Models and Applications. Springer.

Opricovic, S. (1998). Multicriteria optimization of civil engineering systems. Faculty of Civil Engineering, Belgrade, 2(1), 5-21.

Pramanik, S., Dalapati, S., Roy, T.K. (2018). Neutrosophic multi-attribute group decision making strategy for logistics center location selection. Neutrosophic Operational Research, 3, 13-32.

Roy, B. (1968). Classement et choix en présence de points de vue multiples. Revue franiaise d'informatique et de recherche opérationnelle, 2(8), 57-75.

Saaty, T.L. (1978). Modeling unstructured decision problems - the theory of analytical hierarchies. Mathematics and Computers in Simulation, 20(3), 147-158.

Saaty, T.L. (1996). The ANP for Decision Making with Dependence and Feedback. RWS Publications, USA.

Sahu, A.K., Sahu, N.K., Sahu, A.K. (2016). Application of modified MULTI-MOORA for CNC machine tool evaluation in IVGTFNS environment: an empirical study. International Journal of Computer Aided Engineering and Technology, 8(3), 234-259.

Smarandache, F. (1999). A Unifying Field in Logics. Neutrosophy: Neutrosophic Probability, Set and Logic. American Research Press, Rehoboth.

Stanujkic, D., Zavadskas, E.K., Brauers, W.K., Karabasevic, D. (2015). An extension of the MULTIMOORA method for solving complex decision-making problems based on the use of interval-valued triangular fuzzy numbers. Transformations in Business and Economics, 14(2B), 355-377.

Stanujkic, D., Zavadskas, E.K., Karabasevic, D., Smarandache, F., Turskis, Z. (2017a). The use of the pivot pairwise relative criteria importance assessment method for determining the weights of criteria. Romanian Journal of Economic Forecasting, 20(4), 116-133.

Stanujkic, D., Zavadskas, E.K., Smarandache, F., Brauers, W.K., Karabasevic, D. (2017b). A neutrosophic extension of the MULTIMOORA method. Informatica, 28(1), 181-192.

Tian, Z.P., Zhang, H.Y., Wang, J., Wang, J.Q., Chen, X.H. (2016). Multi-criteria decision-making method based on a cross-entropy with interval neutrosophic sets. International Journal of Systems Science, 47(15), 35983608.

Uluçay, V., Deli, I., Şahin, M. (2018). Similarity measures of bipolar neutrosophic sets and their application to multiple criteria decision making. Neural Computing and Applications, 29(3), 739-748.

Wallenius, J., Dyer, J.S., Fishburn, P.C., Steuer, R.E., Zionts, S., Deb, K. (2008). Multiple criteria decision making, multiattribute utility theory: Recent accomplishments and what lies ahead. Management Science, 54(7), 1336-1349.

Zadeh, L.A. (1965). Fuzzy sets. Information and Control, 8(3), 338-353.

Zavadskas, E.K., Turskis, Z. (2010). A new additive ratio assessment (ARAS) method in multicriteria decisionmaking. Technological and Economic Development of Economy, 16(2), 159-172.

Zavadskas, E.K., Kaklauskas, A., Sarka, V. (1994). The new method of multicriteria complex proportional assessment of projects. Technological and Economic Development of Economy, 1(3), 131-139.

Zavadskas, E.K., Turskis, Z., Kildiené, S. (2014). State of art surveys of overviews on MCDM/MADM methods. Technological and Economic Development of Economy, 20(1), 165-179. 
Zavadskas, E.K., Antucheviciene, J., Razavi Hajiagha, S.H., Hashemi, S.S. (2015). The interval-valued intuitionistic fuzzy MULTIMOORA method for group decision making in engineering. Mathematical Problems in Engineering. Art. No. 560690.

Zeleny, M. (1973). Compromise programming. In: Cochrane, J.L., Zeleny, M. (Eds.). Multiple Criteria Decision Making. University of South Carolina Press, Columbia, SC, pp. 262-301.

Zhang, W.R. (1994). Bipolar fuzzy sets and relations: a computational framework for cognitive modeling and multiagent decision analysis. In Proceedings of Industrial Fuzzy Control and Intelligent Systems Conference, December 18-21, 1994, San Antonio, USA, pp. 305-309.

D. Stanujkic is an associate professor of information technology at the Technical Faculty in Bor, University of Belgrade. He has received his MSc degree in information science and $\mathrm{PhD}$ in organizational sciences from the Faculty of Organizational Sciences, University of Belgrade. His current research is focused on decision-making theory, expert systems and intelligent decision support systems.

D. Karabasevic is an assistant professor at the Faculty of Applied Management, Economics and Finance, University Business Academy in Novi Sad. He obtained his degrees at all the levels of studies (BSc appl. in economics, BSc in economics, academic specialization in the management of business information systems and $\mathrm{PhD}$ in management and business) at the Faculty of Management in Zajecar, John Naisbitt University, Belgrade. His current research is focused on the human resource management, management and decision-making theory.

E.K. Zavadskas is a professor of the Department of Construction Management and Real Estate, director of Institute of Sustainable Construction, and Chief Research Fellow of Laboratory of Operational Research at Vilnius Gediminas Technical University, Vilnius, Lithuania. He has a PhD in building structures (1973) and DrSc (1987) in building technology and management. He is a member of the Lithuanian and several foreign Academies of Sciences. He is doctor honoris causa at Poznan, Saint Petersburg, and Kiev universities. He is the editor in chief and a member of editorial boards of a number of research journals. He is an author and coauthor of more than 400 papers and a number of monographs. Research interests are: building technology and management, decision-making theory, automation in design and decision support systems. 
F. Smarandache is a professor of mathematics at the University of New Mexico, USA. He has published many papers and books on neutrosophic set and logic and their applications and has presented to many international conferences. He got his MSc in mathematics and computer science from the University of Craiova, Romania, PhD from the State University of Kishinev, and post-doctoral in applied mathematics from Okayama University of Sciences, Japan.

W.K.M. Brauers, doctor honoris causa Vilnius Gediminas Technical University, was graduated as: $\mathrm{PhD}$ in economics (un. of Leuven), Master of Arts (in economics) of Columbia University (New York), master in economics, master in management and financial sciences, master in political and diplomatic sciences and bachelor in philosophy (all in the University of Leuven). He is professor ordinarius at the Faculty of Applied Economics of the University of Antwerp, honorary professor at the University of Leuven, the Belgian War College, the School of Military Administrators and the Antwerp Business School. His scientific publications consist of eighteen books and several hundreds of articles and reports in English, Dutch and French. 